\title{
Multiplex single-tube screening for mutations in the Nijmegen Breakage Syndrome (NBS1) gene in Hodgkin's and non-Hodgkin's lymphoma patients of Slavic origin
}

\author{
Pavel Soucek ${ }^{1}$, Ivan Gut ${ }^{1}$, Marek Trneny ${ }^{2}$, Eva Skovlund ${ }^{5}$, Grethe Grenaker Alnaes ${ }^{4}$, \\ Tom Kristensen ${ }^{3}$, Anne-Lise Børresen-Dale ${ }^{4}$ and Vessela N Kristensen*,4
}

\begin{abstract}
${ }^{1}$ Biotransformations Group, Center of Occupational Diseases, National Institute of Public Health, Prague 10, 10042 , Czech Republic; ${ }^{2}$ Ist Department of Internal Medicine, University Hospital, U nemocnice 2, Praha 2, 128 08, Czech Republic; ${ }^{3}$ Department of Biochemistry, University in Oslo, Norway; ${ }^{4}$ Department of Genetics, Norwegian Radium Hospital, Montebello 0310, Oslo, Norway; ${ }^{5}$ Department of Institute for Cancer Research, Norwegian Radium Hospital, Montebello 0310, Oslo, Norway
\end{abstract}

Patients with Nijmegen Breakage Syndrome (NBS) have a high risk to develop malignant diseases, most frequently B-cell lymphomas. It has been demonstrated that this chromosomal breakage syndrome results from mutations in the NBS1 gene that cause either a loss of full-length protein expression or expression of a variant protein. A large proportion of the known NBS patients are of Slavic origin who carry a major founder mutation 657del5 in exon 6 of the NBS1 gene. The prevalence of this mutation in Slav populations is reported to be high, possibly contributing to higher cancer risk in these populations. Therefore, if mutations in NBS1 are associated with higher risk of developing lymphoid cancers it would be most likely to be observed in these populations. A multiplex assay for four of the most frequent NBS1 mutations was designed and a series of 119 lymphoma patients from Slavic origin as well as 177 healthy controls were tested. One of the patients was a heterozygote carrier of the ACAAA deletion mutation in exon $6(1 / 119)$. No mutation was observed in the control group, despite the reported high frequency $(1 / 177)$. The power of this study was $30 \%$ to detect a relative risk of 2.0 .

European Journal of Human Genetics (2003) 11, 416-419. doi:10.1038/sj.ejhg.5200972

Keywords: Nijmegen Breakage Syndrome; B-cell lymphomas; Slavic; multiplex assay

Introduction

Nijmegen Breakage Syndrome (NBS) is an autosomal recessive chromosomal instability disorder similar to the ataxia telangiectasia (AT) resulting in microcephaly, growth retardation, and immunodeficiency. Malignancies of lymphoid origin at young age present with defects in the

*Correspondence: Dr VN Kristensen, Institute for Cancer Research, The Norwegian Radium Hospital, Montebello 0310, Oslo, Norway. Tel: 0047229344 17; Fax 0047229344 40;

E-mail: nedelcheva.vessela@dnr.uio.no

Received 11 June 2002; revised 28 January 2003; accepted 29 January 2003 cell cycle check points and increased sensitivity to ionising radiation. ${ }^{1-3}$ Moderately elevated cancer risk for heterozygote carriers of mutations in the ATM gene has been reported for leukemias, non-Hodgkin's lymphomas and breast cancer. ${ }^{4}$

The gene (NBS1) of a size of $56 \mathrm{~kb}$ is localised on $8 \mathrm{q} 21.3$, and codes for a gene product termed Nbs1, p95, or nibrin of 754 amino acids. ${ }^{5}$ The protein is an essential part of a multifunctional complex involved in DNA double-strand break repair and response to radiation. Interactions of nibrin with $B R C A 1$ and $A T M / A T R$ have been shown upon DNA damage. ${ }^{6}$ Nibrin forms a complex with Mre11, and Rad50 in vivo, ${ }^{7}$ which has suggested functions in both 
homologous recombination and nonhomologous endjoining and also a role in telomere maintenance. Nibrin is itself essential for some catalytic activities of this complex such as ATP-dependent partial unwinding of a DNA duplex ${ }^{8}$ and the ATM-dependent activation (phosphorylation) of Chk2 upon gamma radiation. ${ }^{9}$ The abrogation of this activation leads to entry into mitosis immediately after radiation suggesting that checkpoint defects may result from inability to activate Chk2. However, evidence for Nbs1-dependent phosphorylation of CHK2 has been obtained from some cell lines, ${ }^{9}$ but not in others, where repair defects rather than a check point arrest have been proposed as a mechanism to increased radiosensitivity. ${ }^{10}$ Nibrin has been shown to be essential in the radiation-induced phosphorylation of Mre11 (human meiotic recombination 11 ), by recruiting specific kinases. ${ }^{11}$ Initially, the $657 \mathrm{del} 5$ allele was suggested to lead to a premature stop and a truncated protein giving a surprisingly mild phenotype, given that the mouse NBS1 knockout leads to early embryonic lethality. ${ }^{12}$ Recently, an alternative translation was shown to lead to a variant, possibly partly functional NBS1 protein. ${ }^{13}$ Using screening techniques designed to detect carriers of the common mutations Varon et al found an unexpectedly high carrier frequency of the $657 \mathrm{del} 5$, which may contribute to cancer frequency in the studied Slav populations. ${ }^{14}$ To verify that we designed a study for the simultaneous screening for the mutations in NBS1 in the following positions: exon 6, 657 delACAAA, 698 delAACA, exon 7, 835delCAGA, 842 insT, and exon 10, 1142 delC.

\section{Materials and methods Subjects}

Blood samples were obtained from 119 patients with Hodgkin's and non-Hodgkin's lymphoma. The recruited patients comprised of white Slavic Caucasians attended the $1^{\text {st }}$ Department of Internal Medicine of the University Hospital in Prague. The following data on patients were retrieved from medical records: age, sex, clinical stage, presence of symptoms, nodal status, tumour size and grade, histopathological classification of tumour, performance status, international prognostic factor, chemotherapy, and result of chemotherapy. A control group was composed of 177 unrelated subjects of Caucasian origin. Controls were recruited mainly from staff of National Institute of Public Health, $3^{\text {rd }}$ Medical Faculty, and inhabitants of houses for elderly citizens living in the same urban area as patients. Controls had no previous medical record of lymphoma or other cancer disease. The composition of control group was comparable to cases in terms of age and sex (83 females and 94 males, prevalence of subjects older than 50). Patients and controls were asked to read and sign an Informed Consent in agreement with requirements of the Ethical Commission of the National Institute of Public Health in Praha.

\section{DNA extraction}

Genomic DNA was isolated from peripheral lymphocytes by the phenol/chloroform extraction method followed by ethanol precipitation according to standard protocols.

\section{Mutation screening}

A single tube, multiplex PCR analysis of the major known mutations in NBS1 was developed using the three primer pairs given in Table 1.

DNA (50-100 ng) were mixed with 30 pmol of each primer, $0.2 \mathrm{mM}$ of each dNTP, $1.2 \mathrm{mM} \mathrm{MgCl}_{2}$, PCR Buffer II from Perkin-Elmer $\left(\mathrm{MgCl}_{2}\right.$-free), and $0.75 \mathrm{U}$ Taq polymerase (Perkin-Elmer Cetus, Norwalk, CT, USA) in a final volume of $30 \mu \mathrm{l}$. After initial denaturation at $93^{\circ} \mathrm{C}$ for $30 \mathrm{~s}$, amplification was accomplished using a protocol with 20 cycles including $30 \mathrm{~s}$ at $94^{\circ} \mathrm{C}, 30 \mathrm{~s}$ at $62-42^{\circ} \mathrm{C}$ with a decrement of $1^{\circ}$ in each cycle, and $30 \mathrm{~s}$ at $72^{\circ} \mathrm{C}$, followed by 10 cycles with annealing temperature $49^{\circ} \mathrm{C}$ in each cycle, with a final extension of $10 \mathrm{~min}$ at $72^{\circ} \mathrm{C}$ in a PE9600 cycler. The fragment lengths of the PCR products were $136 \mathrm{bp}$ for exon 6, $140 \mathrm{bp}$ for exon 7, and $160 \mathrm{bp}$ for exon 10 of NBS1 (Figure 1). Primers were labelled with FAM for exon 6, HEX for exon 7 and TET for exon 10. After completion of the multiplex PCR reaction with labelled primers, the mix was analysed by a single run of capillary electrophoresis on ABI PRISM $^{\mathrm{TM}} 310$. Running conditions at voltage $15 \mathrm{kV}, 5 \mathrm{~s}$ injection time and a length of run of $24 \mathrm{~min}$ were set for optimal detection of the polymorphic alleles.

Table 1 Multiplex PCR for known mutations (column 2), PCR primer sequences and size of the product

\begin{tabular}{|c|c|c|c|c|}
\hline Primer & Position & Mutations & & $P C R(b p)$ \\
\hline NBSex6FAM & Exon 6 & $\begin{array}{l}657 \text { delACAAA } \\
698 \text { del AACA }\end{array}$ & $\begin{array}{l}\text { 5'-Fam CC ACC TCT TGA TGA ACC ATC TAT } 3^{\prime} \\
5^{\prime} \text { AAT TTA GCT TAT AAC ATA ATT ACC } 3^{\prime}\end{array}$ & 134 \\
\hline NBSex10TET & Exon 10 & 1142 delC & $\begin{array}{l}5^{\prime} \text {-Tet-TTT CTA CAG GGA TTT GAG TGA AAG } 3^{\prime} \\
5^{\prime} \text { TCT CAT CTT AGC CAA AGT ATT TGA TACC } 3^{\prime}\end{array}$ & 160 \\
\hline
\end{tabular}




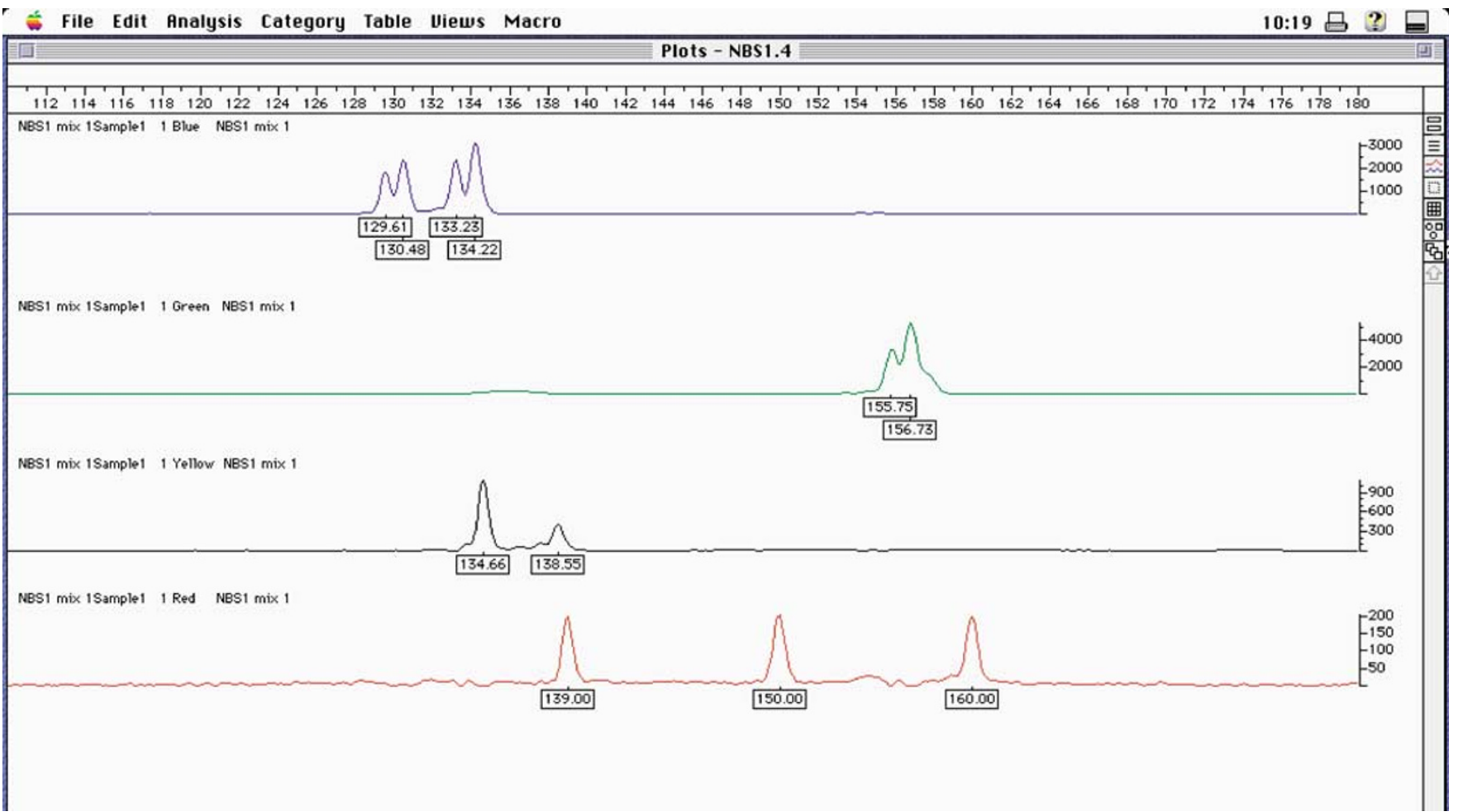

Figure 1 Multiplex PCR reaction was analysed by a single run of capillary electrophoresis on $A B I$ PRISM ${ }^{\mathrm{TM}} 310$. The fragment lengths of the PCR products, $134 \mathrm{bp}$ for exon 6, $140 \mathrm{bp}$ for exon 7, and $160 \mathrm{bp}$ for exon 10 of NBS1 for the homozygous wt are given relative to the internal standard. Primers were labelled with FAM for exon 6 (two blue peaks for a heterozygous deletion of $5 \mathrm{bp}$ ), HEX for exon 7 (two black peaks for a heterozygous deletion of $4 \mathrm{bp}$ ) and TET for exon 10 (two green peaks for a heterozygous deletion of $1 \mathrm{bp}$ ). Running conditions at voltage $15 \mathrm{kV}, 5 \mathrm{~s}$ injection time and a length of run of 24 min were set for optimal detection of the polymorphic alleles.

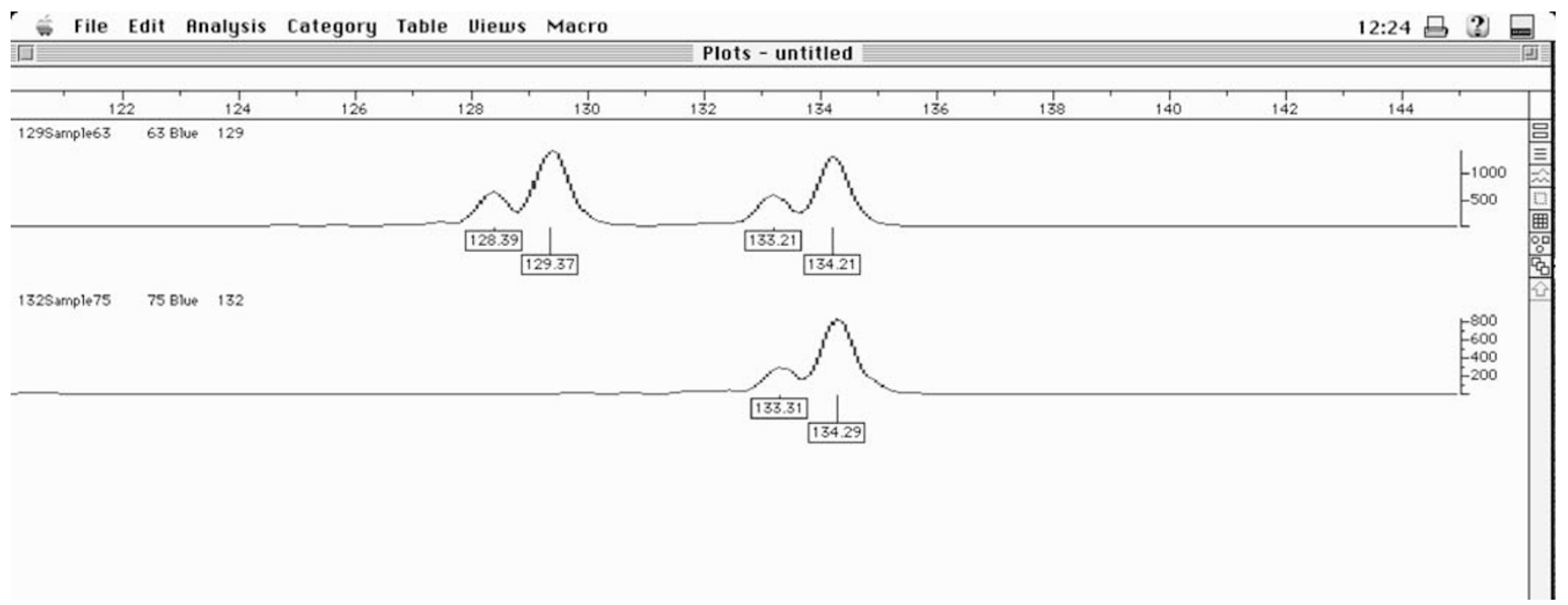

Figure 2 A non-Hodgkin's lymphoma patient presenting with heterozygote deletion of ACAAA exon 6.

\section{Results}

A single tube, multiplex PCR-based method for screening of the major known mutations in NBS1 has been developed (Figure 1). Using this method we screened for mutated
NBS1 alleles in 119 lymphoma patients of Czech origin and 177 controls. In addition, the studied exons (exons 6, 7, and 10) have been amplified separately and sequenced to verify the results in 11 randomly chosen patients and 13 
controls. One of the patients was a heterozygote carrier of the ACAAA deletion mutation in exon 6 (1/119) (Figure 2). No mutation was observed in the control group, despite the reported high frequency $(1 / 177)^{14}$ of the $657 \mathrm{del} 5$ mutation in Slavic populations. The present study does not therefore report an increased relative risk for lymphoma patients carrying the Slavic mutation although it was observed in one of the patients $(n=119)$ and in none of the controls $(n=177)$. The probability of finding no mutations, if the true probability in the population is $P$, can be calculated as follows (using the formula for the binomial distribution):

$$
P(X=0)=\left(\begin{array}{l}
n \\
0
\end{array}\right) p^{0}(1-p)^{n-0}
$$

In our example $n=119$ and $P=0.005$ (or $1 / 177$ ) the probability of observing one mutation would be $0.995^{119}=0.55$. If the true probability was twice that observed in the control population $(P=2 / 177)$ then it is $0.99^{119}=0.30(P=0.01)$, that is, our study had a $30 \%$ probability to detect an $\mathrm{RR}=2$.

\section{Discussion}

Both Hodgkin's and non-Hodgkin's lymphomas constitute a diverse group of malignancies with respect to histology, clinical presentation and disease progression. Genetic polymorphisms in xenobiotic metabolising enzymes of the cytochrome $P 450$ and glutathione $S$-transferase superfamilies may contribute to disease risk. ${ }^{15}$ The possible involvement of mutations in the NBS1 gene in the pathogenesis of lymphoid diseases is suggested by the fact that this is the most common form of malignancy suffered by NBS patients. ${ }^{1}$ Furthermore, mutations in the gene were found in some cases (14.9\%) of childhood acute lymphoblastic leukemia ${ }^{15}$ but not large deletions in the NBS1 area on chromosome $8 \mathrm{q} .{ }^{17}$ Since at least one of the known variants, $657 \mathrm{del} 5$ in exon 6 , was found in $1 / 177$ healthy individuals of Slav origin, ${ }^{14}$ we believed that it is feasible to expect a higher frequency of carriers of this mutation in lymphoma patients of the same population. Our results did not confirm this hypothesis in the studied patient groups. A larger set of both cases and controls is under investigation. However, the rapid and convenient screening technique that we introduce in this study could be used for larger population screening or for patient groups with increased radiosensitivity and abnormal response to radiation treatment.

\section{Acknowledgements}

This work was supported with research grant $122772 / 310$ by the Norwegian Cancer Society, exchange grant from the International
Department of University in Oslo for guest researcher Pavel Soucek, as well as grant IGA 6747-3 of the Internal Grant Agency of Czech Ministry of Health.

\section{References}

1 Gatei M, Young D, Cerosaletti KM et al: ATM-dependent phosphorylation of nibrin in response to radiation exposure. Nat Genet 2000; 25: 115-119.

2 Varon R, Vissinga C, Platzer M et al: Nibrin, a novel DNA doublestrand break repair protein, is mutated in Nijmegen breakage syndrome. Cell 1998; 93: 467-476.

3 Seemanova E: An increased risk for malignant neoplasms in heterozygotes for a syndrome of microcephaly, normal intelligence, growth retardation, remarkable facies, immunodeficiency and chromosomal instability. Mutat Res 1990; 238: 321-324.

4 Olsen JH, Hahnemann JM, Borresen-Dale AL et al: Cancer in patients with ataxia-telangiectasia and in their relatives in the nordic countries. J Natl Cancer Inst 2001; 93: 84-85.

5 Matsuura S, Tauchi H, Nakamura A et al: Positional cloning of the gene for Nijmegen breakage syndrome. Nat Genet 1998; 19: 179-181.

6 Zhong Q, Chen CF, Li S, Chen Y, Wang CC, Xiao J, Chen PL, Sharp ZD, Lee WH: Association of BRCA1 with the hRad50hMre11-p95 complex and the DNA damage response. Science 1999; 285: 747-750.

7 Carney JP, Maser RS, Olivares H et al: The hMre11/hRad50 protein complex and Nijmegen breakage syndrome: linkage of doublestrand break repair to the cellular DNA damage response. Cell 1998; 93: 477-486.

8 Paull TT, Gellert M: Nbs1 potentiates ATP-driven DNA unwinding and endonuclease cleavage by the Mre11/Rad50 complex. Genes Dev 1999; 13: 1276-1288.

9 Buscemi G, Savio C, Zannini L et al: Chk2 activation dependence on Nbs1 after DNA damage. Mol Cell Biol 2001; 21: 5214-5222.

10 Girard PM, Foray N, Stumm M et al: Radiosensitivity in Nijmegen Breakage Syndrome cells is attributable to a repair defect and not cell cycle checkpoint defects. Cancer Res 2000; 60: 4881-4888.

11 Dong Z, Zhong Q, Chen PL: The Nijmegen breakage syndrome protein is essential for Mre11 phosphorylation upon DNA damage. J Biol Chem 1999; 274: 19513-19516.

12 Zhu J, Petersen S, Tessarollo L, Nussenzweig A: Targeted disruption of the Nijmegen breakage syndrome gene NBS1 leads to early embryonic lethality in mice. Curr Biol 2001; 11: 105-109.

13 Maser RS, Zinkel R, Petrini JHJ: An alternative mode of translation permits production of a variant NBS1 protein from the common Nijmegen breakage syndrome allele. Nat Genet 2001; 27: 417-421.

14 Varon R, Seemanova E, Chrzanowska $\mathrm{K}$ et al: Clinical ascertainment of Nijmegen breakage syndrome (NBS) and prevalence of the major mutation, 657del5, in three Slav populations. Eur J Hum Genet 2000; 11: 900-902.

15 Sarmanova J, Benesova K, Gut I, Nedelcheva-Kristensen V, Tynkova L, Soucek P: Genetic polymorphisms of biotransformation enzymes in patients with Hodgkin's and nonHodgkin's lymphomas. Hum Mol Genet 2001; 10: 1265-1273.

16 Varon R, Reis A, Henze G, Einsiedel HG, Sperling K, Seeger K: Mutations in the Nijmegen breakage syndrome gene (NBS1) in childhood acute lymphoblastic leukemia (ALL). Cancer Res 2001; 61: 3570-3572.

17 Stanulla M, Stumm M, Dieckvoss BO et al: No wevidence for a major role of heterozygous deletion of $657 \mathrm{del} 5$ within the NBS1 gene in the pathogenesis of non-Hodgkin's lymqphoma of childhood and adolescence. Br J Haematol 2000; 109: 117-120. 